Olivera I. Simić ${ }^{1}$

UDC: 81'276-053.4

OŠ „Sveti Sava” Požarevac

Pregledni rad

Aleksandra D. Jović

DOI: $10.19090 /$ zop.2021.30.27-53

PU „Petar Pan” Kragujevac

\title{
KULTURA OBRAĆANJA, OSLOVLJAVANJA I POZDRAVLJANJA U GOVORU DECE PREDŠKOLSKOG UZRASTA
}

Apstrakt.U radu je dat pregled različitih jezičkih pojava koje su obrađivane u dosadašnjim istraživanjima kod nas, kao i pregled radova na temu obraćanja, pozdravljanja i oslovljavanja. Jedan od ciljeva je da se skrene pažnja na složenost načina na koji deca predškolskog uzrasta uspostavljaju komunikaciju. Predstavljen je fenomen i osnovno određenje govora i jezika, etimologija reči obraćanje i oslovljavanje, načini obraćanja, oslovljavanja i pozdravljanja dece u predškolskom uzrastu. Istaknut je značaj porodice i predškolske ustanove kao bitnih faktora za razvoj verbalne komunikacije kod dece, a samim tim i bogatstva rečnika i inventara reči i izraza za pozdravljanje i oslovljavanje. Način komunikacije se kod dece vremenom formira i menja pod uticajem vrtića/škole, porodice i bliže okoline. Boravak dece u vrtiću postaje svakodnevna životna situacija koja nudi pregršt mogućnosti za pravilan razvoj govora i načina uspostavljanja komunikacije.

Ključne reči: komunikacija, obraćanje, oslovljavanje, pozdravljanje, predškolski uzrast

\section{UVOD}

Govorni činovi pozdravljanja i oslovljavanja, kao društvenokonvencionalni obrasci ponašanja, mogu biti preduslov uspešne komunikacije, ali i izvor namernih ili iz neznanja započetih nesporazuma. Kao prvi korak verbalne ili neverbalne, javne ili privatne, pismene ili usmene komunikacije, ovi govorni činovi su uslovljeni mnogobrojnim kulturnim, lingvističkim i nelingvističkim faktorima kao što su stepen

\footnotetext{
${ }^{1}$ Olivera Simić, oljamarija89@gmail.com
} 
poznatosti, kontekst (mesto, vreme, pol i uzrast), socijalni status, bliskost, kulturno ili jezičko nasleđe itd. Uspešna komunikacija zahteva prilagođavanje ovih činilaca $\mathrm{i}$ to je jedna od najvažnijih sposobnosti koje u procesu vaspitavanja treba razvijati kod dece.

Istraživanjem dosadašnjih radova sa sličnom tematikom, sagledan je način na koji deca predškolskog uzrasta komuniciraju, odnosno koje forme pozdravljanja, obraćanja i oslovljavanja koriste u komunikaciji jedni sa drugima i u komunikaciji sa vaspitačem. Ova istraživanja nisu brojna, a oslovljavanjem u predškolskom uzrastu detaljnije su se bavile Vera Vasić (1979), Mirjana Jocić (1981), te Svenka Savić i Ivona Žibreg (1982).

U početnom delu rada dat je osvrt na osobine i strukturu srpskog jezika, osnovno određenje pojma govora i jezika, a zatim su predstavljene forme pozdravljanja, obraćanja i oslovljavanja koje se kod nas najčešće koriste. Ukazano je na značaj pedagoške komunikacije, oblike razgovora kao i na lične i psihodinamičke aspekte razgovora. Predstavljeni su neki aspekti oslovljavanja, pozdravljanja i obraćanja u govoru dece predškolskog uzrasta. Ovaj period razvoja govora, a samim tim i komunikacije, veoma je važan jer u predškolskom periodu deca uče da stupaju u kontakt sa drugim osobama, da se prilagođavaju različitim govornim situacijama, razvijaju društvenu senzibilnost. Bitan faktor ovog razvoja je socijalno iskustvo, odnosno kontakti koje je dete uspostavilo odmalena. Komunikacija je za dete uspostavljanje odnosa sa drugima, sredstvo izražavanja misli i osećanja, razmena poruka... 


\section{GOVOR I JEZIK}

Jezik je najsavršeniji i najefikasniji sistem sredstava međuljudskog sporazumevanja, najdublje srastao sa čovekovim društvenim životom.

U svakodnevnoj komunikaciji, govor sagovornika ukazuje na uzrast, pol, vaspitanje zdravstveno stanje, fizičku kondiciju, emocionalnu zrelost i stabilnost, kao i na intelektualni nivo. Sve ove informacije može dobiti sagovornik koji ume da sluša.

Termini govor i jezik se upotrebljavaju kao sinonimi, ali u savremenoj lingvistici su njihova značenja razdvojena. Jezik predstavlja sistem znakova kojim se ljudi sporazumevaju, dok je govor individualno korišćenje jezika. Drugačije rečeno ,govor je zvučna manifestacija jezika ili zvučna realizacija jezika čoveka kao pojedinca” (Miljković, 2015: 155). Govor je i glasovna komunikacija, izgovaranje reči i rečenica, to je jezik u praksi i/ili jezik u akciji. Može se zaključiti da je jezik homogeni sistem znakova određenog kolektiva, određene zajednice, odnosno društvena kategorija. Govor je individualna kategorija, odnosno pojedinačan govor ili verbalno korišćenje jezičkih znakova od strane pojedinca.

Govor se sastoji od govorno-fizioloških, akustičko-fonetskih i grafičkih vrednosti. Može biti usmeni i pisani. Usmeni govor je verbalno ostvarenje jezika a pismeni govor ili pisanje ostvaruje se upotrebom grafičkih sredstava. Postoji i znakovni govor, zasnovan na grimasama i gestikulaciji. Sve tri vrste govora - usmeni, pisani i znakovni zapravo govore o raznim mogućnostima individualne upotrebe jezika (Miljković, 2015: 155).

Ljudski jezik, kao način sporazumevanja, ima socijalnu prirodu. Jezik je sistem društveno uslovljenih znakova čija je osnovna funkcija komuniciranje i uopštavanje, dok govor nastaje u okviru jezika kao njegov oživljeni deo (Vigotski, 1983). Ako uzmemo u obzir ovakvo shvatanje 
jezika, pojam govora možemo razumeti kao individualnu realizaciju jezika jer će ona uvek biti drugačija, zavisiće od uzrasta, kulturnog nivoa i drugih odlika indivudue. Govor (jezik) je jedan od determinišućih činilaca opšteg razvoja deteta. Posebno je provokativno pitanje društvenog uticaja na razvoj govora i odatle, praktičnih implikacija na vaspitno-obrazovni proces. Govor je temelj veštine početne pismenosti - čitanja i pisanja. Receptivni jezik se odnosi na jezik koji dete prima slušajući (ili čitajući), dok je ekspresivni jezik onaj kojim se dete služi kada govori ili piše (Naumović, 2000).

Jezik je sistem znakova koji je sredstvo sporazumevanja među ljudima. Jezikom čovek saopštava svoje misli i osećanja. Ovo znači da je jezik društvena pojava, da je njegov postanak vezan za postanak i razvoj ljudskog društva. Kao najsavršenije sredstvo sporazumevanja on je vezan za misao, pa su mišljenje, svest i jezik u stalnom jedinstvu. Sa usavršavanjem misli, usavršava se i jezik, i sa usavršavanjem jezika razvija se i mišljenje (Stanojčić i Popović, 2002). Prema Bugarskom (2005), pored ključne uloge koju igra u mišljenju, spoznavanju i tumačenju stvarnosti, jezik u svim društvima obavlja niz kulturnih, estetskih, obrednih i drugih funkcija, ali njegov osnovni zadatak jeste da služi kao prikladno sredstvo društvene interakcije i komunikacije.

Jezik i govor su u potpunosti međusobno uslovljeni. Jedan jezik ne bi mogao postojati ako se ne ostvaruje u govoru a govor ne bi postojao da ne proizilazi iz jezika. Drugačije rečeno ,govor se razvio na bazi jezika, odnosno u stalnom, uzajamnom dejstvu i prožimanju usled kojeg se menjaju i jedno i drugo" (Bugarski, 1995: 16). 
Ljudi svakodnevno razgovaraju, razmenjuju poruke, iznose informacije sa određenim svrhama i normama, u različitim situacijama, porodičnim, školskim, uličnim, profesionalnim... Komunikacija je postala životni uslov bez koga se ne može, pogotovo u poslednjih pedesetak godina tokom kojih je došlo do ekspanzije tehnoloških sredstava (radio, televizija, mobilna telefonija, internet). Globalizacijom sveta ljudima je omogućen višestruko veći broj kontakata tokom života. Čovek svakodnevno šalje i prima poruke u najrazličitijim vidovima: kao reči (izgovorene ili napisane), kao pokretne slike, animacije, gestove i dr. Ljudi daju i traže obaveštenja, prenose jedni drugima svoja znanja i iskustva.

Čovek najveći deo svoga vremena provodi u komunikaciji sa drugim ljudima, što je u skladu sa određenjem da je čovek društveno biće. Međutim, pri govornom komuniciranju, svaku poruku, osim samih reči, čine još dve komponente: korišćenje glasa (ton glasa, njegova boja, brzina govora, glasnoća, izgovor, pauze u govoru) i korišćenje tela (mimika, gestikulacija). Čovek se pri interakcijama licem u lice ponajviše usredsređuje na svoje reči, pa zaboravlja kako pritom njegovi pokreti, stavovi i izrazi lica kazuju svoju priču.

Neverbalna komunikacija se sastoji od mnoštva znakova. Svakodnevno komuniciramo uz pomoć tih znakova i „čitamo” ih kod drugih ljudi. Mnoge gestove apsorbujemo iz socijalne sredine u kojoj živimo i oni se tokom našeg života snažno modifikuju nesvesnim podražavanjem društvenih običaja.

Vizuelni znaci koji se koriste u saobraćaju razumljivi su svim vozačima i takođe spadaju u neverbalna sredstva. U vidove neverbalnih 
sredstava spadaju i znakovni jezik osoba sa oštećenjem sluha, Morzeova azbuka kao metoda prenošenja signala tj. poruka na daljinu, Brajevo pismo za slepe i slabovide i drugo.

U Pravilniku o opštim osnovama predškolskog programa (2006) istaknuto je da za ukupan razvoj deteta presudnu ulogu ima socijalna interakcija sa odraslima i vršnjacima. Ovaj razvojni period se opisuje na sledeći način:

- period bogat razvojnim potencijalima, period u kome se razvija veliki deo inteligencije i perceptivnih sposobnosti, period u kome dete ima odlično pamćenje i intenzivan senzomotorni i ikonički razvoj;

- period u kome nastaje diferenciranje motiva i emocija, počinju da se ispoljavaju interesovanja i unutrašnja motivacija za predmete od interesa i interakcije sa vršnjacima;

- predškolska deca, međutim, imaju skroman logičko-analitički aparat, perceptivno su fiksirana i vezana za kontekst u kome uče, imaju problema sa apstrahovanjem i izražavanjem zbog malog fonda reči i jezičkih mogućnosti, potrebne su im konkretne aktivnosti i slikovit način prikazivanja i označavanja stvari i pojava.

Zanimanje za podsticanje jezika i govora u predškolskom periodu javilo se u velikoj meri kao posledica jezičkih nedostataka kod pojedine dece. Podsticanje razvoja jezika predškolskog deteta može dovesti do napretka kognicije. Prema Banduri (1977), govor i mišljenje su dva aspekta istog procesa. Razvoj govora ima veliki uticaj na razvoj mišljenja i obrnuto. 
Ključna je uloga vaspitača, kasnije i učitelja, u izgrađivanju pravilnog govora. Zbog toga bi trebalo da oni predstavljaju dobar uzor govora, ličnosti koje motivišu decu na usvajanje dobrih obrazaca govora.

Usvajanje govornih uzora najuspelije je ako deca zažele da se identifikuju - poistovete sa svojim vaspitačima/nastavnicima i neosetno da usvajaju govor vaspitača/nastavnika. Naša ispitivanja razvitka artikulacije kod dece na uzrastu od 3 do 9 godina pokazala su da veza između artikulacije učitelja, vaspitača i njihovih ispitanika nesumljivo postoji, i da se procenat zajedničkih činilaca kreće od $25 \%$ do $56 \%$. Osim toga, ukoliko vaspitač ima veći broj negativnih artikulacionih crta u govoru, utoliko će više uticati na svoje ispitanike, pogotovo ako između njih postoji i emocionalna veza. Otuda se pitanju govora onih koji se bave obrazovnim procesom mora posvetiti posebna pažnja (Vasić, 1977: 28).

Lukić (1982) smatra da ispitivanje dečijeg govora i dečijeg rečnika pruža puno podataka o zakonitostima razvitka govora i jezika, kao i mišljenja uopšte. Suština nastave maternjeg jezika ne sastoji se samo u upoznavanju maternjeg jezika, njegovih osobina i strukture, već i u sticanju sposobnosti da se jezik koristi kao nezaobilazni činilac intelektualnog razvoja, i to u doba kada se na taj razvoj može najviše uticati. Od jezičko razvijene misli i jezičkog ponašanja umnogome zavisi usvajanje svih znanja u skoli, razvoj mišljenja i formiranje određenog pogleda na svet. $\mathrm{Na}$ pravilno postavljenoj nastavi maternjeg jezika leži glavni deo odgovornosti za pravilno formiranje govornog (jezičkog) ponašanja (Lukić, 1982). U knjizi Metodika nastave srpskog jezika i književnosti u razrednoj nastavi, Vuk Milatović (2011) vezuje za predbukvarski period posebne zadatke koji se odnose na neposrednu pripremu za čitanje i pisanje. To su: a) vizuelne vežbe ili vežbe u posmatranju; b) akustične vežbe ili vežbe u slušanju; v) prepričavanje i pričanje; g) opisivanje; d) vežbe artikulacije; đ) vežbe disanja i e) razumevanje i usvajanje pojma glasa, reči i rečenice. 
Veličina rečnika je broj reči kojima dete aktivno raspolaže. Broj reči se razlikuje i zavisi od uzrasta deteta ali i od podsticaja okoline, kao i od inteligencije deteta. Vasić (1977) naglašava da se prilikom procenjivanja opsega dečijeg rečnika vrši kvantitativna analiza.Vaspitač treba da nastoji da poveća značenja jedne reči, da vodi računa o pravom značenju upotrebljenih reči, o kvalitetu, više nego o broju reči koje dete upotrebljava prilikom svog izražavanja.

Vaspitač treba kontinuirano sprovoditi različite govorne igre. Deca uživaju u igrama poput traženja reči koje počinju ili se završavaju istom fonemom, traženja reči koje se rimuju, traženja pitanja i odgovora na zadatu reč, imitacija, pričanja priča, dijaloških vežbi i slično. Predmet razgovora može biti slikovnica, razgledanje ilustracija, šetnja u prirodi ili gradu, boravak u dvorištu.

Do šeste godine deca uglavnom nauče da izgovaraju sve glasove maternjeg jezika. Poneka deca imaju problema sa izgovaranjem pojedinih glasova (r, dž, č, ̌̌, 1) što se rešava vežbanjem sa logopedomi praktikovanjem govornih igara i to samo sa decom koja imaju poteškoće te prirode, a ne sa celom vaspitnom grupom. Možemo zaključiti da je tada fonološki razvoj, uglavnom, završen (Ivanović, 1997).

Deca uzrasta od četiri do sedam godina na planu komunikacije i govora su ovladala određenim veštinama komunikacije, njihov govor dovoljno je artikulaciono, rečenički i gramatički razvijen tako da mogu uspešno da se sporazumevaju sa osobama iz socijalne sredine, posebno sa onima koje dobro poznaju. 
Dalje napredovanje u govoru usmereno je na sticanje komunikativnih sposobnosti (učenje upotrebe govora, prilagođavanje govora situaciji, ali i korišćenje govora za pričanje o onome što se desilo i što će se eventualno desiti), objašnjavanje iskaza, bogaćenje rečnika, proširivanje značenja reči, razumevanje govora drugih, širenje saznanja o rečima, glasovima, na jačanje stvaralačkih jezičkih kapaciteta. Dalji pravci razvoja govora su samo okvirna orijentacija. Na tom putu svako dete treba da korača svojim tempom, uz stalnu podršku vaspitača (Ivanović, 2014: 11).

Kada je reč o semantičkom planu (plan značenja reči) treba istaći da se ,u ovom periodu ubrzano povećava aktivni rečnik: dete od tri godine koristi 700 reči, a dete sa šest godina koristi oko 2500 do 3000 reči" (Ivanović, 1997: 16).

Kada je reč o sintaksi (plan rečenice) „dete koristi proste, prostoproširene i neke složene rečenice. Snalazi se u potvrdnim, odričnim i upitnim značenjima, ali ima problema sa nekim tipovima odnosnih, odnosno relativnih rečenica"(Ivanović, 1997: 16).

Deca ovog uzrasta prepričavaju priče, pričaju po slikama, postavljaju pitanja i odgovaraju na njih. Sa pet godina prepoznaju neka slova azbuke, da bi se oko šeste godine pojavilo interesovanje za pisani govor. Ovo je samo početak razvoja komunikacijskih sposobnosti. Jedini način da ih dete dalje razvija jeste korišćenje govora za iskazivanje različitih sadržaja vezanih za samoizražavanje, za životno-praktične situacije, za razvoj imaginacije i sl. Aktivnom upotrebom govora dete uči za šta se sve govor koristi, istovremeno razvijajući eksplicitnost i komunikacijsku prikladnost.

Organizovanjem i spovođenjem igrovnih aktivnosti poput telefoniranja, u autobusu, prilikom susreta dva drugara, upoznavanja sa nepoznatom osobom i slično, u kojima će deca aktivno učestvovati, 
omogućavamo im da razvijaju komunikacijsku prikladnost, odnosno sposobnost da se verbalno snalaze u svim situacijama.

Pored komunikacijske prikladnosti i eksplicitnog izražavanja, dete dalje treba da razvija aktivni rečnik, da uči značenje reči i diferencijaciju značenja reči (homonimi, sinonimi, deminutivi, augmentativi, građenje reči i slično). To se, pored ostalog, postiže korišćenjem odabranih umetničkih tekstova, praktikovanjem raznovrsnih igara $\mathrm{i}$ korišćenjem govora $\mathrm{u}$ svakodnevnim životnim situacijama. Važan zadatak je i korišćenje govora kao sredstva izražavanja mišljenja sa napomenom da sam govor dece ne treba sputavati. Na ovom uzrastu deca imaju sposobnost da „stvaraju vrlo raznovrsne jezičke tvorevine: neobične reči, nova imena, stihove, priče, izokrenute stihove, ređalice $\mathrm{i} \mathrm{dr}$, pa ovu njihovu sposobnost treba $\mathrm{i}$ dalje razvijati” (Ivanović, 1997: 17).

Iz navedenog možemo zaključiti da obrazovno-vaspitne aktivnosti moraju biti brižljivo planirane i osmišljene od strane vaspitača (kasnije učitelja i nastavnika) i usmerene ka usvajanju novih znanja i ka razvoju ličnosti deteta.

Komunikaciju možemo shvatiti kao razmenu ideja, misli i osećanja putem verbalnih i neverbalnih znakova i simbola, zarad ostvarivanja nekih zajednčkih ciljeva. Suzić (2003) navodi da komunikacija ima veoma široko, i za čovekov razvoj, esencijalno značenje. Komunikacija, međutim, ne podrazumeva samo razmenu informacija, već pretpostavlja i ponašanje ljudi u njihovim međusobnim interakcijama. To je slojevit i višesmeran proces, te ne čudi što nije uvek i uspešan. Različiti uticaji mogu otežati sporazumevanje. Moguće smetnje ipak ne treba da obeshrabre učesnike u 
komunikaciji. Mogućnosti sporazumevanja su izuzetne, a čovek raspolaže sredstvima da ove probleme ublaži (Suzić, 2003).,Ukoliko unapređuje kulturu govora i slušanja i razvija komunikacijske veštine, učesnik razgovor može učiniti podsticajnim i svrhovitim.Za uspešnu dvosmernu komunikaciju i stvaranje prijatne atmosfere važno je da svi učesnici budu angažovani, da aktivno slušaju i poštuju sagovornike” (Đorđević, 2004: 42).

Kvalitetna komunikacija je posebno važna u određenim profesijama. Vaspitački i nastavnički poziv jedan je od onih koji zahtevaju visok nivo osposobljenosti u oblasti komuniciranja i međuljudskih odnosa uopšte. Komunikacija se nalazi u samoj osnovi obrazovanja, ona je istovremeno i sredstvo i cilj nastavnog delovanja. Kako komunikacija u vaspitnoobrazovnim uslovima ima svoje zakonitosti i osobenosti, razvio se pojam pedagoška komunikacija.

Tokom različitih perioda razvoja pedagoške misli različito se pristupalo problemu komunikacije u nastavi. Prema Đorđeviću (2004), savremena nastava počiva na humanističkim načelima i interakciji između učesnika nastave, a njen osnovni zadatak je emancipacija dečije ličnosti. Poštovanje i prihvatanje sagovornika, tolerancija i kooperativnost su osnovne odlike demokratskog načela komunikacije.

Važno je pitanje šta pedagošku komunikaciju izdvaja od ostalih vidova komunikacije. Komunikacija u vaspitno-obrazovnim uslovima svakako poštuje opšte karakteristike socijalnih interakcija, ali i neke posebne didaktičko-metodičke osobenosti. Vaspitno-obrazovni proces predstavlja svojevrsni organizovani komunikacioni proces koji podrazumeva uzajamnu interakciju i saradnju između svih učesnika. Kako 
je ovo međusobno delovanje usmereno na ispunjavanje vaspitnih, obrazovnih i razvojnih ciljeva i zadataka, to pedagošku komunikaciju karakteriše „namensko, usmereno usvajanje određenih informacija” (Đorđević, 2004: 43).

Razgovor je sastavni deo vaspitno-obrazovnog procesa. Nastavnik sa učenicima može voditi razgovor u veoma različitim situacijama i sa različitim ciljevima, od kojih su najvažniji: podučavanje - obrazovni cilj, obrada nastavne jedinice ili organizacija neke aktivnosti, usmeravanje, procena uspešnosti i obrazloženje procene, podrška, savetovanje i drugo (Milovanović, 2010).

Prema Pedagoškom leksikonu, komunikacija u vaspitanju podrazumeva saopštavanje, primanje informacija i njihovo prenošenje, razmenu poruka i ,uopšte, uspostavljanje odnosa, način oslobađanja i sporazumevanja između učesnika u vaspitno-obrazovnom procesu." (Potkonjak i Pijanović, 1996: 244).

\section{ETIMOLOGIJA REČI, OBRAĆANJE I OSLOVLJAVANJE}

Ako se zna da je primarna funkcija jezika komunikacija, neosporno je da $\mathrm{u}$ tom procesu prvo mesto pripada samom početku, tj.uspostavljanju komunikacije, budući da bez uspešno uspostavljene komunikacije nje neće ni biti. Kontakt sa sagovornikom obično se uspostavlja kroz neki oblik oslovljavanja. Kako ćemo osloviti sagovornika zavisi od mnogo faktora: da li je potencijalni sagovornik okrenut licem ili leđima, da li je u pitanju poznanik ili nepoznata osoba, starija ili mlađa osoba, kao i brojne druge okolnosti. 
U proučavanju jezika kao sredstva komunikacije ovaj deo mora zauzeti prvo mesto, pri čemu se mora imati u vidu da na izbor jezičkog inventara u ovoj funkciji veliki uticaj imaju brojni nejezički elementi. Ovaj jezički segment obavezno pripada jeziku u upotrebi i najčešće ima usmenu formu, ali u određenima okolnostima svojstvo je i pisanog jezika - u dijalozima u književnom delu, a reklo bi se da je obavezan i u pismima.

U većini radova autora koji su se bavili ovom problematikom, pojam oslovljavanje se ne odvaja odobraćanja već se implicitno uzimaju kao sinonimi ili kao nepotpuni ili delimični sinonimi (Vasić, 1979).

Po naslovima većine ovih radova u čijem je sastavu oslovljavanje i obraćanje reklo bi se da se pod oslovljavanje, tj. obraćanje podvodi i jedno i drugo - i način na koji osoba na samom početku oslovi osobu sa kojom stupa u komunikaciju i obraćanje tokom trajanja komunikacije (na VI ili TI). Istina, ima radova u kojima u naslovu eksplicitno stoji npr. ,lekseme za oslovljavanje" (Žilberg i Savić, 1982) i sl.

Oslovljavanje bi se moglo posmatrati nezavisno od obraćanja, tj. kao deo komunikacije. U toj službi javlja se i etiketa sa značenjima ,imena, prezimena, nadimci, nazivi za označavanje srodstva, zanimanja, profesije, titule, drušvene funkcije, semantički nespecifično obeležena" (Jocić, 2011: 300). Autor dalje ističe da „termin etiketa u sociolingvističkoj literaturi označava reč ili izraz koji služi za oslovljavanje i obraćanje drugoj osobi" (Jocić, 2011: 298).

Za razgraničavanje ova dva termina možda bi se opravdanje moglo naći u (transparentnoj) etimologiji ovih reči. U korenu reči osloviti nalazi se reč slov(o) u značenju 'reč', pa bi osloviti značilo 'uputiti nekome reči 
kojima želimo da skrenemo, tj. pridobijemo njegovu pažnju' i to bi mogla biti vokativna forma imenice sa značenjem titule, srodničkog odnosa i sl. ili nečije lično ime (Vasić, 1979).

U glagolu obratiti (od ob-vratiti), tj. u njegovom korenu je vrat-, tj. vrt-, te značenje ovog glagola glasi 'okrenuti nekoga (u željenom smeru) time što ćemo se oglasiti - reći nešto, kako bismo privukli njegovu pažnju sa namerom da sa njim započnemo razgovor' (Vasić, 1979). Oslovljavanje bi, po pravilu, predstavljalo upotrebu vokativne forme neke imenice (ime, prezime, titular i sl.): Gospođo, ispao vam je novčanik, a u obraćanju je moguća upotreba bilo kojih reči kojima ćemo privući nečiju pažnju, na primer: Izvinite, ispao vam je novčanik i sl.

U Rečniku srpskoga jezika, pod odrednicom osloviti stoji: 'obratiti se kome, obično u govoru (rečima, pitanjem i sl.); započeti razgovor obraćajući se (pozdravom, imenom, titulom i sl.); imenovati, titulisati' (Vujanić i sar., 2011: 876), a pod odrednicom obratiti se zatičemo 'uputiti nekome (pismeno ili usmeno) reči, zahtev, molbu'(Vujanić i sar., 2011: 834). Prema onome što stoji u rečnicima, nema građe koja bi potvrdila jasnu granicu između oslovljavanja i obraćanja. Zapravo, vidljivo je preplitanje semantike ova dva pojma, mada ima elemenata na osnovu kojih bi se moglo diferencirati oslovljavanje od obraćanja. Pod oslovljavanje bi se mogao podvesti početak komunikacije, tj. reči koje predstavljaju ime, titulu, čin, koje upućujemo osobi sa kojim želimo da otpočnemo komunikaciju: Gospodine, da li znate gde je ulica... ili Zemljače, koja je ovo ulica?

$\mathrm{Na}$ drugoj strani, pod obraćanjem bismo podrazumevali komunikaciju: Izvinite, da li znate gde je ulica... Molim vas, da li je ovo put 
$z a \ldots$ i sl., u kojoj se komunikacija inicira nekim formalnim obrascem. Ovom tipu bi pripadala i direktna komunikacija: Da li biste mi otvorili vrata? Ako žuriš, izvoli napred i sl.

\section{FORME POZDRAVLJANJA, OBRAĆANJA I OSLOVLJAVANJA KOD DECE PREDŠKOLSKOG UZRASTA}

Prilikom susretanja, ljudi upućuju jedni drugima različite pozdrave, koristeći se pri tome neverbalnim ili verbalnim sredstvima, ili obično i jednima i drugima u isto vreme. Najčešča neverbalna sredstva pozdravljanja su „rukovanje, zagrljaj, poljubac, klimanje glavom, naklon, podizanje ruke ili mahanje, skidanje šešira...Verbalnim sredstvima, tj, posebnim rečima i izrazima koje ljudi upućuju jedni drugima u znak pozdrava pri susretima, iskazuju se različite želje za dobro zdravlje, mir, sreću, dug život i sl...” (Šipka, 2009: 213). Upotreba verbalnog ili neverbalnog znaka je „određena tradicijom i običajima pojedinih ljudskih kolektiva, a uz to ukazuje i na emocionalne i socijalne odnose onih koji se pozdravljaju. Po svemu tome pozdravljanje je društveno uslovljen čin" (Šipka, 2009: 213).

Način pozdravljanja i oslovljavanja zavisi od mnogo različitih faktora. „Izbor jezičkih sredstava u međusobnom verbalnom saobraćanju i oslovljavanju unutar jedne govorne zajednice društveno je i kulturološki uslovljen, baš kao i u slučaju pozdravljanja. Taj izbor, dakle, ne zavisi od jezičkih, nego od vanjezičkih (društvenih) faktora, pa ga stoga ne regulišu standardnojezički priručnici (gramatike, pravopisi, rječnici)" (Šipka, 2009: 217). Šipka navodi da je izuzetak pravopisna odredba o velikom početnom slovu u pisanju zamenica Vi, Vas, Vaš ,iz poštovanja”. 
Međusobno oslovljavanje komunikatora sa $t i$ sugeriše njihovu biskost i ravnopravnost. Tako se učenici i studenti istih ili bliskih generacija, ili vojnici u kasarni, ili kolege na poslu istoga ranga, ili ideološki istomišljenici (kao što su ranije bili komunisti), ili ljubavni parovi, i drugi čiji odnos karakteriše bliskost ili/i ravnopravnost međusobno oslovljavaju sa $t i$. Obraćanje sa $t i$ iskazuje bliskost i u odnosu dece i roditelja, kao i bližih rođaka, mada to nije svuda tako, čak ni kod nas. Sve to zavisi od tipa kulture i različitih tradicija (Šipka, 2009). Oslovljavanje savi upućuje na „društvenu i emocionalnu distancu komunikatora, na službeni odnos bez bliskosti ili intimnosti, čak i na određenu rezervisanost jednih prema drugima, zbog nedovoljnog poznavanja ili kog drugog razloga” (Šipka, 2009: 219). Kada se komunikatori različito oslovljavaju to ukazuje na neravnopravnost ili nejednakost.

U srpskom jeziku gotovo da nije opisano kako deca oslovljavaju odrasle na različitim uzrastima, niti kako to čine odrasli sa decom.

Deca na ranom uzrastu upotrebljavaju lično ime i termine za označavanje rodbinskih odnosa, a ređe nadimak. Na ranom uzrastu se pojavljuje samo forma $t i$, dok forma vi gotovo sasvim izostaje (Vasić, 1979). Autorka navodi da se dosledna primena zamenice ti odvija u porodici, što znači da je u direktnom govoru sa odraslima dete imalo mogućnost da čuje samo ovu formu. Tek u indirektnom govoru - razgovoru roditelja sa gostima ili prijateljima, u kupovnini itd., dete je moglo da čuje upotrebu $v i$ forme. Formu $t i$ dete nauči kad progovori jer se svi malom detetu obraćaju savi, pa ono imitirajući taj model, svakoga oslovljava sa vi. Upotreba zamenice $v i$ pod jakim je uticajem odraslih. Odrasli će proceniti kada dete treba da počne obraćanje odraslima sa $v i$ i kome će vi najpre reći. 
Deca se u predškolskoj ustanovi obraćaju sati osobama sa kojima se svakodnevno susreću. Pred polazak u školu neka deca će početi da upotrebljavaju zamenicu $v i$ umesto $t i$ u razgovoru sa osobljem u ustanovi. Polazak u školu je poslednji trenutak za početak upotrebe zamenice vi jer se deca učitelju (uglavnom) obraćaju sa $v i$. Učitelj će ih u tom pravcu ispravljati ako deca upotrebe formu $t i$. Roditelji intenzivno ispravljaju kod dece upravo ,pogrešnu” upotrebu forme $t i$ tamo gde bi po njihovoj proceni dete trebalo sa upotrebi formu vi. Postepeno se dete suočava sa činjenicom da u jeziku postoje društvene uloge kao i relativni društveni status $u$ datoj prilici. Starija će deca eksplicitno pitati odrasle da li da neku osobu oslove sa $t i$ ili $v i$. To je period od devete do četrnaeste godine kada deca još nemaju dovoljno iskustva u konverzaciji sa različitim odraslim sagovornicima da bi mogla sa procene kada i kome će reći $t i$, odnosno vi (Kalogjera, 1974).

Komunikativna kompetencija i jezičko znanje dvaju pojedinaca, ma koliko njihove okoline bile bliske ili slične, nikada nisu identični. U svakom slučaju, razlikuju se bar $\mathrm{u}$ individualnoj sposobnosti da primene te kompetencije $\mathrm{i}$ to znanje. Time se broj individualnih poonašanja i idioma umožava - u većoj sredini ih je uvek više. Pošto nema udžbenika i propisanih pravila kojima je ovaj domen ponašanja obuhvaćen, može se zaključiti da sredina, pre svega porodica i obrazovne ustanove, uz medijei internet, utiču na stvaranje navika ove vrste.

\section{PREGLED DOSADAŠNJIH ISTRAŽIVANJA}

Ivona Žiberg i Svenka Savić (1982) u istraživanju Neki aspekti oslovljavanja u govoru dece predškolskog uzrasta navode da su opisi sistema za oslovljavanje u jezicima bili podstaknuti radom američkih 
psihologa Rodžera Brauna (Roger Brown) i Alberta Gilmana (Albert Gilman). Analizirajući primere upotrebe ličnih zamenica za oslovljavanje sagovornika u više evropskih jezika (engleski, francuski, nemački, italijanski...), autori konstatuju T-formu kao zamenicu drugog lica jednine za familijarno oslovljavanje i V-formu kao zamenicu za učtivo oslovljavanje. U vezi sa tim, kao osnovne pojmovno-terminološke kategorije, tj. kriterijume oslovljavanja, uvode solidarnost - što podrazumeva jednakost i bliskost sagovornika i distanciranost ili nesolidarnost - što podrazumeva statusnu nejednakost, službenost, formalnost.

Sva kasnija mnogobrojna istraživanja i rasprave o pravilima upotrebe zameničkih $\mathrm{T} / \mathrm{V}$, odnodno $t i / v i$ oblika, u oslovljavanju sagovornika $\mathrm{u}$ situaciji obraćanja polaze uglavnom od pojmova solidarnost (primer $t i-\mathrm{ti}$ odnosa među sagovornicima), distanciranost (primer $v i$ - vi odnosa) i statusne nejednakosti, razlike (princip $v i-t i$ odnosa). Od istih pojmova se polazi i pri izboru etiketa za pozdravljanja (dobar dan, doviđenja, zdravo, i obrnuto), odnosno etiketa identifikacije po srodstvu (majka, otac), profesiji, zanimanju (učitelj/učiteljica, frizer/frizerka), tituli i zvanju (doktor, docent/docentkinja, primarijus), društvenoj i državnoj funkciji (predsednik/predsednica, ministar/ministarka, rektor/rektorka), po semantički neutralnim obeležjima (gospodin, gospođa, drug, drugarica, komšija/komšnica, čika, teta) itd. Važna univerzalna, za sve jezike važeća činjenica, o isprepletenosti jezika sa drugim društvenim fenomenima koji utiču na jezičku upotrebu i modifikuju je, rezultirala je stavom da raznolikost jezičkih upotreba zavisi od raznolikosti vanjezičke situacije (Žiberg i Savić, 1982). 
Del Hajmz (Hymes, 1980, prema Jocić, 2011) je tu univerzalnu sposobnost prilagođavanja jezika vanjezičkoj situaciji nazvao komunikativnom kompetencijom, što zapravo podrazumeva sistem društvenih vrednosti i pravila, bonton određene društvene zajednice, odnosno društvene grupe: ko prvi pruža ruku, ko se prvi javlja, kako se ponašati $\mathrm{u}$ privatnoj a kako $\mathrm{u}$ javnoj sferi, kako $\mathrm{u}$ formalnoj a kako $\mathrm{u}$ neformalnoj situaciji i sl.

Detaljno opisujući ovu vrstu društveno uslovljene kompetencije, Radovanović naziva to ,gramatikom” društvenog statusa i naglašava da ,problematika ove vrste, inače, po pravilu izostaje iz desktiptivnih ili normativnih serbokroatističkih priručnika..." (Radovanović, 1986: 132). Nedostatak takvih jezičkih priručnika i društveno dogovorenih pravila komunikativnog ponašanja najviše pogađa javnu sferu, pre svega masovne medije, zatim statusno označene okvire kao što su: škola, organi vlasti, sudnica, vojska, crkva itd. Deo tih pravila daje se u vidu saveta i preporuka u knjigama o lepom ponašanju.

Jasminka Petrović (2004) u svojoj knjizi Bonton - bez dlake na jeziku između ostalog piše: „Pri upoznavanju pružite ruku i rukujte se, ni suvuše jakim stiskom, ni suviše slabim, i izgovorite svoje ime. Oslovljavajte sagovornika sagospođo i gospodine, a nikako sa ej, ti. Ako se dvoumite da li da se nekome obratite savi ili sa $t i$, pre se odučite za vi” (Petrović, 2004: 76).

U prvoj decenijiXXI veka pojavljuju se i obimnija istraživanja u kojima se, uz sumiranje rezultata ranijih istraživanja, kompleksnije pristupa ovoj temi (Jocić, 2011). Svi se istraživači slažu da su oslovljavanje i pozdravljanje društveno uslovljena jezička ponašanja, pa je zadatak nauke o 
jeziku da objasni osnovne principe na osnovu kojih takvo jezičko ponašanje funkcioniše u različitim privatnim, kao i javnim i službenim sferama.

Istraživanja razvoja govora dece nisu mogla ostati izvan opštih istraživanja u psiholingvistici i sociolingvistici. Tako su se podaci o načinima oslovljavanja odraslih i dece našla u mnogim studijama poslednjih godina u kojima se opisuju različiti neindoevropski jezici. Pritom su od velike važnosti za sagledavanje opšte slike stanja u normalnim uslovima usvajanja govora i podaci iz govora dece čiji je razvoj iz bilo kojih razloga ometen: kod slepe dece, kod dece sa usporenim mentalnim razvojem, autizmom ili emocionalnim poremećajima.

Podaci iz ovih istraživanja mogu da objasne šta je to što se u sistemu oslovljavanja odvija kod dece prilikom socijalizacije u govornoj sredini. $\mathrm{Na}$ primer, s obzirom na odsustvo vizuelne percepcije sagovornika kod slepe dece, saznanje o prisustvu sagovornika pre početka komunikacije obezbeđuje se eksplicitnim pitanjem - Jesi li tu? Ili, kod autistične dece koja mogu da vide sagovornika, ali im nedostaje intencija za obraćanje i oslovljavanje, eksplicitno oslovljavanje sagovornika najčešće izostaje.

Vera Vasić (1979) opisuje načine na koje dete predškolskog uzrasta u porodici oslovljava odraslu osobu. Navodi šta utiče na odabir jezičkog znaka koji dete ima kad oslovljava odraslu osobu:

„...uzrast deteta, sociokulturna sredina (prvenstveno porodična), individualna obeležja vezana za odraslu osobu, i obeležja koja karakterišu vezu između odrasle osobe i deteta. Ovi činioci mogu se odrediti kao varijabilni, što dozvoljava da se pretpostavi da će deca različitog uzrasta, koja odrastaju u porodicama sa različitim sociokulturnm navikama, razvijati i upotrebljavati različite modele oslovljavanja" (Vasić, 1979: 175). 
Važno je starosno doba odraslih članova porodice, zatim onih osoba koje imaju česte kontakte sa decom, a najvažniji je stav odraslih članova porodice prema modelu oslovljavanja koje razvija dete (na primer, dete kaže odrasloj osobi „Miro”, a majka ga ispravlja: „Nije Mira nego tetka Mira”). Zaključak autorke je da su roditelji sve ispitivane dece na ranom uzrastu upotrebljavali sledeće načine oslovljavanja: Reč za obeležavanje rodbinskog odnosa, lično ime (roditelja) i kombinaciju ovih dvaju - obeležavanje rodbinskog odnosa + lično ime (tetka Nena, ujak Neca). Shodno modelu u govoru odraslih, deca takođe formiraju nekoliko načina oslovljavanja odraslih. Zaključak autorke da dete dosledno jednu odraslu osobu oslovljava na jedan način, a drugu (u istom tipu rodbinskih odnosa) na drugi - jedna tetka je teta, a druga je tetka Mira, važan je za uočavanje kako se različitosti formiraju u govoru deteta. Ukratko, važan je nalaz da više različitih načina oslovljavanja odrasle osobe već postoji u govoru predškolskog deteta na ranom uzrastu (kada potpuno izostaje oslovljavanje odraslih osoba etiketama gospodin, gospođa, gospođica, drug).

U drugom radu, štampanom nekoliko godina kasnije, autorka pokazuje kako starija braća i sestre doprinose razvoju govora mlađeg deteta, pa i u domenu oslovljavanja i samooslovljavanja. Autorka je posmatrala decu u spontanim situacijama u porodicama u kojima ima vise od jednog deteta. U njenom radu su izneti dragoceni podaci o postepenom formiranju sistema za oslovljavanje od ranog do školskog uzrasta i doprinosu odraslih i starije dece u tom procesu. Autorka daje inventar verbalnih znakova za oslovljavanje: lično ime, samo glagolska forma (Daj mi), (Vasić, 1983).

Predškolska ustanova, kao jedan od bitnih faktora razvoja i socijalizacije deteta, veoma je podsticajna i za razvoj verbalne komunikacije 
kod dece, a u okviru toga i inventara reči i izraza za oslovljavanje i pozdravljanje. Da bi se dobilo što više podataka o različitim tipovima govorne komunikacije koji u predškolskoj ustanovi čine sastavni deo svakodnevne komunikacije između dece i između dece i vaspitača, u predškolskoj ustanovi u Novom Sadu, Jocić (1981) je sprovela istraživanje tokom jedne školske godine. Prisustvujući svim aktivnostima grupe dece od tri do četiri godine i beležeći podatke o situacionom kontekstu, autorka je pažnju usmerila pre svega na komunikaciju vaspitačice sa decom. Konstatuje da je komunikaciju obično započinjala vaspitačica, da se ona najčešće obraćala čitavoj grupi dece koristeći se etiketama i izrazima (obično uz povišenu intonaciju) Deco! Dečice! Mili moji... Mali moji... 'Ajde da.../Hajde da... Idemo... itd. Kada se obraćala deci pojedinačno koristila je najčešće ime deteta (Iva, pevaj! Ratko, sedi lepo! Šta želiš, Nadice?), kao i hipokoristične etikete dušo, srce, sine, maco... Naravno, svakom detetu se obraćala zamenicom $t i$ i glagolskim oblikom u jednini. Deca su vaspitačicu oslovljavala formom Ti i njenim ličnim imenom (Jocić, 1981).

Ivona Žibreg i Svenka Savić (1982) konstatuju da deca na ranom uzrastu u porodici koriste samo formu ti za sve osobe koje susreću (poznate: otac, majka, baka ali i za nepoznate). Podaci su sakupljani iz realnih razgovornih situacija dece sa roditeljima i drugim osobama, uz brižljivo beleženje situacije i konteksta u kojima su izgovoreni takvi primeri. Autorke procenjuju da se prelazak od forme $t i$ na formu vi kod dece predškolskog uzrasta, kao znak veće društvene senzibilnosti, događa ulaskom u školsku sredinu, ali uočavaju individualne razlike među posmatranom decom. U grupi su bila deca i muškog i ženskog pola, ali autorke ne registruju podatke 
o razlikama koje se tiču pola dece, niti se bave razlčitim neverbalnim znacima pozdravljanja (kao što je mahanje rukom). To su komponente koje ce se pojaviti kasnije i u istraživanjima stranih autora, a tek sporadično i u istraživanjima domaćih. Iz ovog istraživanja važni su i podaci koji ukazuju na to da uzrast ima značajnu ulogu u odabiru jezičkog znaka za oslovljavanje, pored kriterijuma stepena poznatosti, bliskosti ili društvene moći.

\section{ZAKLJUČAK}

Osnovni cilj rada je skretanje pažnje na kompleksnost načina na koji se individua, konkretno dete predškolskog uzrasta, uključuje u društvenu zajednicu u želji da joj se na pravi način predstavi. Pored toga, ukazano je na promene koje su u XXI veku zabeležene u svetskoj literaturi, pre svega u metodu opisa činjenica koje su uslovile i pomeranje fokusa istraživanja kod nas, a tiču se odnosa jezika i društva - jer je jezik društveno uslovljen.

U radu je ukazano na to kako se sistem oslovljavanja kod dece formira i menja u pravcu onog kakav je u upotrebi kod odraslih i izneta je tvrdnja da je povezan sa očekivanjima koja imaju najpre roditelji, a zatim i vaspitači/učitelji, uža/šira okolina.

Prvobitni sistem za oslovljavanje kod dece predškolskog uzrasta sadrži, pored reči za oslovljavanje (lično ime, nadimak, termini za označavanje rodbinskih odnosa, zamenički oblici $t i$, ređe $v i$ ), i kontaktne forme poput evo, eto, eno, ej, vidi, pogledaj, halo i sl. O oslovljavanju, obraćanju i pozdravljanju kao oblicima socijalnog govornog ponašanja pisano je kao o pojavi koja zavisi od statusa, uzrasta, zanimanja, poznatosti sagovornika i drugo. 
S obzirom da su govorni činovi pozdravljanja i oslovljavanja društveno konvencionalni obrasci ponašanja i uslov uspešne komunikacije, ova tema pruža mogućnosti za dublja i opširnija istraživanja u različitim društvenim kontekstima. 


\title{
PRESCHOOL CHILDREN'S CULTURE OF APPROACHING, ADDRESSING, AND GREETING
}

\begin{abstract}
The paper presents an overview of different linguistic forms that have been treated in previous research in our country, as well as a review of papers on the topic of approaching, addressing, and greeting. An aim is to draw attention to the complexity of the way in which preschool children establish communication. The paper also presents the phenomenon and basic definition of speech and language, etymology of words "addressing" and "approaching", preschool children's ways of addressing, approaching, and greeting. There has been emphasized the importance of family and preschool institutions as substantial factors for the development of children's verbal communication and richness in vocabulary, inventory of words and expressions for greeting and addressing. The way of communication is formed over time, and it changes under the influence of kindergarten/school, family and the environment. Kindergarten attendance becomes an everyday life situation for children, which offers a handful of opportunities for proper speech development and ways to establish communication.
\end{abstract}

Key words: addressing, approaching, greeting, communication, preschool age 


\section{REFERENCE}

Bandura, A. (1977). Social learning theory. Englewood Cliffs : Prentice Hall.

Bugarski, R. (2005). Jezik i kultura. Beograd: Biblioteka XX vek.

Bugarski, R. D. (1995). Uvod u opštu lingvistiku. Beograd: Zavod za udžbenike i nastavna sredstva.

Đorđević, J. (2004). Nastava kao proces poučavanja, učenja i komunikacije. Zbornik radova Komunikacija i mediji u savremenoj nastavi. 37-50.

Ivanović, R. (1997). Govorne radionice za rad sa decom od 3 do 7 godina. Beograd: Altera.

Ivanović, R. (2014). Deca imaju reč, deca u govornim razmenama. Beograd: Kreativni centar.

Jocić, M. (1981). Tipovi jezičke adaptacije u obraćanju vaspitača deci. U: Mišeska Tomik (ur.) Jezikot vo javnata komunikacija (168-176). Skopje.

Jocić, M. (1981): Osobine jezičkog komuniciranja vaspitača sa decom predškolskog uzrasta. Prilozi proučavanju jezika, 17, 103-117.

Jocić, M. (2011). Oslovljavanje i obraćanje. Lingvističke sveske, 9. 297346.

Kalogjera, D. (1974). U prilog pojmu komunikativne kompetencije. Kultura, 25, 138-146.

Lukić, V. (1982). Dečja leksika, Beograd: Institut za pedagoška istraživanja. Milatovic, V. (2011). Metodika nastave srpskog jezika $i$ književnosti u razrednoj nastavi, Beograd: Učiteljski fakultet.

Milovanović, R. (2010). Interakcija i komunikacija u vaspitnom radu. Jagodina: Pedagoški fakultet.

Miljković, M. (2015). Jezik i kultura.Zbornik radova Učiteljskog fakulteta u Prizrenu-Leposaviću, 9, 153-164.

Naumović, M. (2000). Metodika razvoja govora: priručnik za studente viših škola za obrazovanje vaspitača $i$ vaspitače. Pirot: Viša škola za obrazovanje vaspitača.

Petrović, J. (2010). Bonton bez dlake na jeziku. Beograd: Kreativni centar. 
Potkonjak, N. i Pijanović, P. (1996). Pedagoški leksikon. Beograd: Zavod za udžbenike i nastavna sredstva.

Pravilnik o Opštim osnovama predškolskog programa (2006). Beograd: Službeni glasnik RS - Prosvetni glasnik, br. 14/2006 od 15.11.2006. god.

Radovanović, M. (1986). Sociolingvistika. Novi Sad: Književna zajednica Novog Sada, Dnevnik.

Suzić, N. (2003). Efikasna pedagoška komunikacija. Nastava $i$ vaspitanje, 52(2-3), 254-273.

Stanojčić, Ž. i Popović Lj. (2002). Gramatika srpskog jezika. Beograd: Zavod za udžbenike i nastavna sredstva.

Šipka, M. (2009). Kultura govora (četvrto izdanje). Novi Sad: Prometej.

Vasic, S. (1977). Govor u razredu, Beograd: Prosveta.

Vasić, V. (1979). Tipovi oslovljavanja odrasle osobe u govoru dece predškolskog uzrasta. Godišnjak Saveza društava za primenjenu lingvistiku Jugoslavije, 3, 175-180.

Vasić, V. (1983). Govor sestre sa bratom. Novi Sad: Filozofski fakultet, Institut za južnoslovenske jezike.

Vigotski, L. (1983). Mišljenje i govor. Beograd: Nolit

Vujanić, M. i sar. (2011). Rečnik srpskoga jezika. Novi Sad: Matica srpska. Žibreg I. i Savić, S. (1982). Neki aspekti oslovljavanja u govoru dece predškolskog uzrasta. Prilozi proučavanju jezika, 18, 5-26. 
